\title{
Shell companies - Identification of an instrument used for illicit purposes: A Pitch
}

\author{
Milind Tiwaria,1 \\ ${ }^{a}$ Bond University, Australia
}

\begin{abstract}
This pitch letter describes the personal application of the pitching tool developed by Faff $(2015,2018)$ to a potentially academic topic related to money laundering and corruption in the early stages of research. The pitch template aids in the identification of core elements that form the framework for research. The author provides a brief overview of the experience of using the pitch template and its potential applications.
\end{abstract}

Keywords: Pitching research; shell companies; money laundering; model development

JEL codes: C51, C53, M40

\section{Introduction}

Similar to Unda (2015), Rekker (2016) and Wallin \& Spry (2016), this pitch letter describes the application of "pitching research" template developed by Faff (2015), and regularly revised such as by Faff $(2017,2018)$, to a potential academic research topic in the field of money laundering. With regards to my academic and professional background, I am currently pursuing my M.Phil. at Bond University, Gold Coast, Australia and have worked in the field of fraud and anti-money laundering investigations with firms such as KPMG and EY and hold relevant certifications in the area. My interests around shell companies and more broadly in the field of money laundering and fraud investigations stems from my work experience as a forensic risk consultant.

${ }^{1}$ Corresponding author: Milind Tiwari, Bond University, 14, University Drive, Robina, Queensland - 4226, Australia, e-mail address milind.tiwari@student.bond.edu.au 
I started my course in January 2018, so I have just completed a few months of my degree and am still in the early stages. As part of my degree, I was required to complete "RBUS6914 - Process of Research in Business" to aid my skill development and undertook it in the first semester of my degree (March 2018). The course aimed to explore the ways researchers could use the pitching template to articulate their thoughts into a research proposal and convey it in the most succinct manner possible. Initially, I had inhibitions about the course, and I was not sure of the kind of value and knowledge I would gain and the ways I could use the pitching template given the early stage I was in my degree. I faced difficulty in conveying the knowledge gained by working in the field and through my initial readings to my supervisors in a concise manner. However, the "pitching" framework helped me overcome that difficulty. Faff $(2015,2018)$ "pitching" framework acted as a tool to align my ideas and identify research opportunities and concisely present the same to an academic expert.

I started using the "pitching" framework to reverse-engineer the relevant literature and identify potential opportunities for further research. The ability to comprehend the literature efficiently helped me articulate my thoughts and turned out to be an essential step in generating innovative research ideas. Stokes (2013) highlights the need for generating creative research ideas keeping in mind factors such as the intersection of a researcher's passion, the journal's interest, and the researcher's skills to conduct research. The pitching framework helps in accomplishing just that by incorporating various elements in the tool.

My application of the pitching template was different from many of my peers in that I used the template towards the development of a topic for my proposed research. I, initially, used the tool to reverse engineer relevant literature and then used the comprehended material to come up with a related topic in the area. The pitching tool acted as a pathway to explain concisely what is done, why it is exciting and what it adds to the literature, consistent with the views of Bradbury (2012) required for gaining the attention of editors and readers alike.

My approach for the pitch completion was non-linear and was formulated by using the pitching tool to reverse-engineer relevant literature and then using the same framework to propose a new topic. The adoption of tool to reverse-engineer relevant literature on shell companies, corruption and fraud detection models aided me in the formulation of my research idea by identifying key papers (Item E) for my research. With regards to '3-2-1' template design, the idea of the research, along with the motivation, was identified through gap-spotting the relevant literature. Further, the data (Item F) was available through Transparency International UK. Transparency International UK, an anti-corruption NGO, used open-source data from various investigation reports dating back to 2004, records and leaked documents from Open Corporates and UK Companies House, in its report published in 2017 called "Hiding 
in Plain Sight: How UK Companies are used to Launder Corrupt Wealth" (Cowdock, 2017). Regarding Tools (Item G), a brief description was provided due to lack of awareness of various techniques that could be used for development of the model. The limitations regarding the same were highlighted in Other Considerations (Item K) along with other assessment of obstacles in research related to its outcome. Additionally, the guidance required from supervisors related to their field of expertise was also mentioned in Other Considerations (Item K). Finally, the significance of the research was established through What's New and So What (Items $\mathrm{H}$ and I) and concluded with the holy grail, that is, Contribution (Item J).

The rest of the paper is organized as follows: Section 2 provides a brief commentary on the pitch. Section 3 highlights personal reflections about the pitch exercise followed by the last section outlining the conclusion.

\section{Brief Commentary on the Pitch}

Table 1 shows the completed pitch on shell companies. The primary objective of the study as stated in the Basic Research Question (Item B) of the pitch template was to develop a model to identify shell companies being used for illicit purposes. This pitch laid down the foundation of the work I would be undertaking as part of my M.Phil. and PhD. The critical papers identified were Allred et al. (2017), Alstadsæter et al. (2018) and Song et al. (2014). Allred et al. (2017) and Alstadsæter et al. (2018) provide an overview of the existing literature surrounding shell companies, and Song et al. (2014) gives a direction into using various techniques for the development of a model. The motivation for my study originated from the use of shell companies as a tool for illicit purposes such as bribery, corruption, tax evasion, terrorist financing and so forth. Therefore, making it essential to identify and distinguish whether a shell company is being used for an illicit purpose or not. The critical elements of the research are explained through Idea, Data and Tools (Item E, F, and G respectively). Idea draws light on the core idea and central hypothesis of my research along with the existence of a theoretical tension. Data provides a brief overview of the dependent variable and the possible independent variables for the study. Tools that are meant to be used to carry out the research are yet to be identified, and hence a brief description is provided of what is intended to be used. The novelty and the significance of the study are explained through Items $\mathrm{H}$ and I, namely, What's New and So What. Further, the contribution the study is likely to make to the literature is also specified in the pitch template. Other considerations consider the resources needed to complete the research and the possible obstacles that might come during its course. 
Table 1: Completed 2-page template on Shell Companies

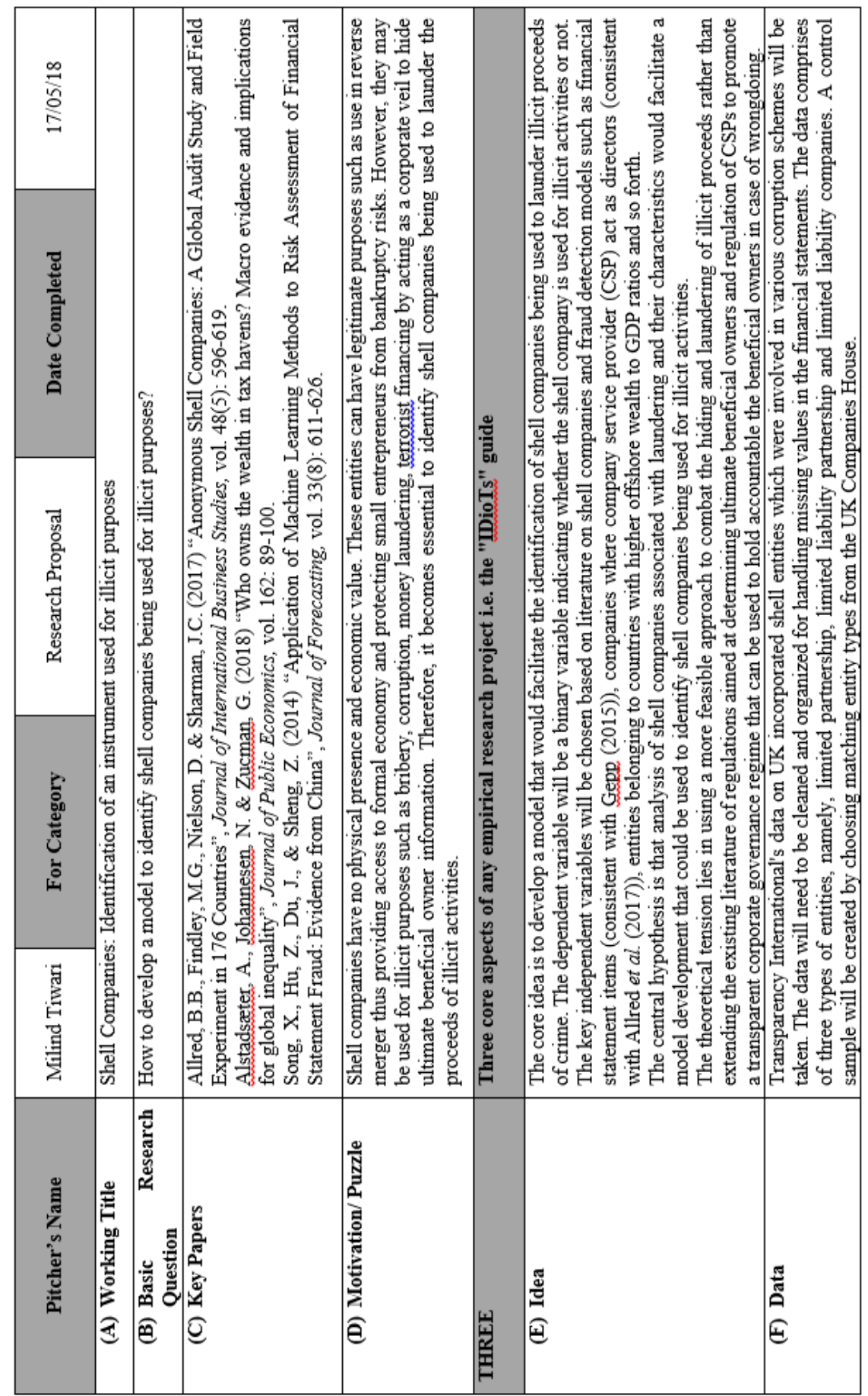




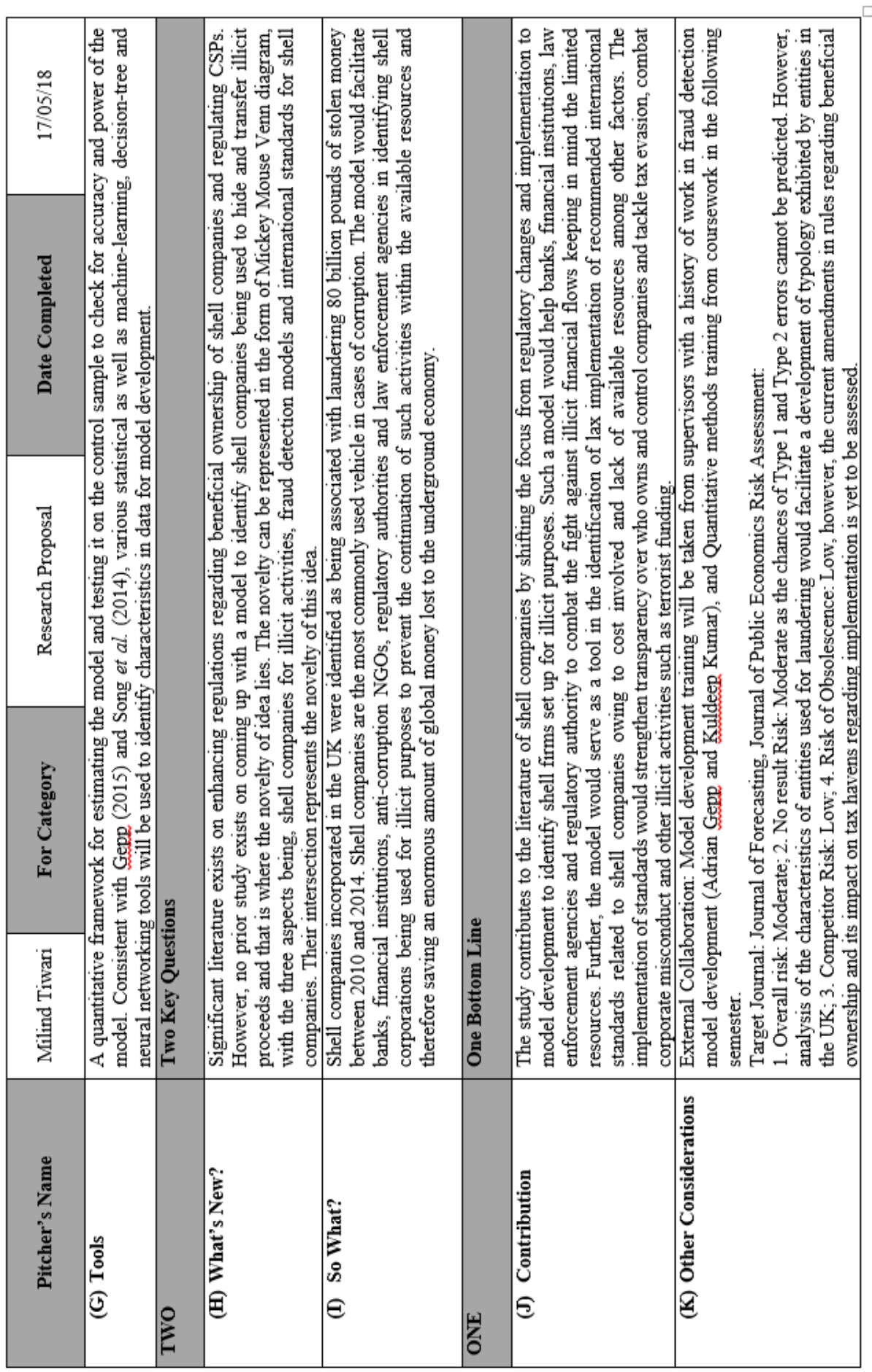

Vol. 17, No. 4 


\section{Personal Reflections on the Pitch Exercise}

The pitching template has helped to refine my ideas and come up with a potential topic for my research. From my experience so far as well as that of my peers, the pitching template has wide-ranging applications such as reverse engineering of relevant literature (Salehudin, 2017), coming up with new topics of research and facilitating a base for conversation with supervisors (Rekker, 2016), facilitating collaboration (Wallin \& Spry, 2016). As Grant \& Pollock (2011) points out, an introduction sets the expectations for a reviewer from a particular article, and hence it is essential to write a compelling introduction to intrigue the reader and generate interest in the article. I believe the template can be used as a guidance tool to write upon various sections in an article, especially the introduction, as it seeks answers to questions which could contribute in writing an effective introduction. The application of the pitching tool in writing other sections of an article or thesis may also be considered.

I have had some substantial takeaways from using the pitching template. The flexibility in usage of the pitching template at any stage of research is quite beneficial, especially for novice researchers like me, who are in the early stages of their course and require a way to streamline their respective research ideas. I am likely to use the pitching template further as I progress to aid me in my research. Further, the emphasis given upon core elements of research helps in developing clarity of thought by engaging in key aspects of one's research. Moreover, the identification of novelty using Venn Diagram, as presented in Figure 1, enables a researcher to visualize and present the novelty of the idea as well as its significance to the stakeholders. The time spent on thinking about each item in the pitching template and answering them can help in saving a lot of time and confusion in later stages of research by establishing clarity of what needs to be done.

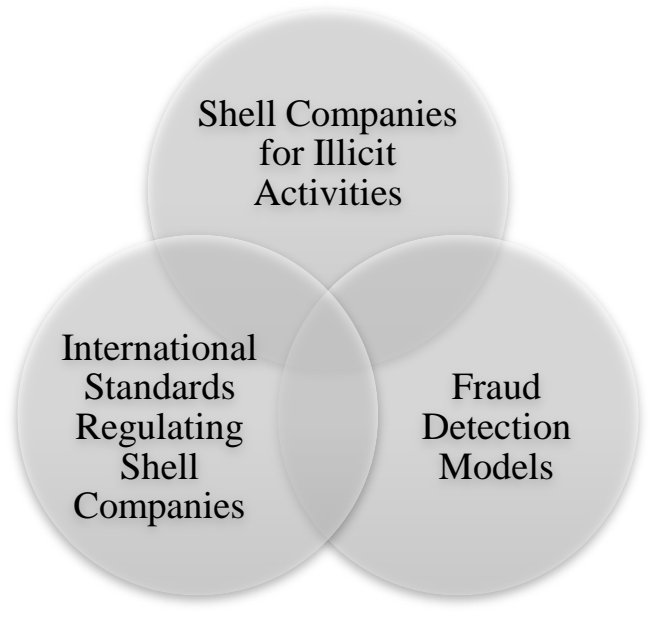

Figure 1: Mickey Mouse Venn Diagram applied to my Pitch 


\section{Conclusion}

This pitch letter provides an explanation of a pitching template example for a topic on money laundering determining the use of shell companies for illicit purposes. The pitch presented was developed during the early stages of the research degree and hence highlights the usage of the pitching tool as developed by Faff $(2015,2018)$ at various stages of the research degree. The formulation of a pitch has given a direction to my future readings as well as multiple aspects which I should focus on to complete my research. The pitching template facilitated a dialogue between my supervisors and me. I have used it extensively as a tool for reverse-engineering of relevant literature and to propose new ideas. The framework tends to provide support to the chosen problem by questioning aspects critical to successful completion of research. I would suggest the use of pitching template to my peers for initiation of conversation, for collaboration, for comprehending existing literature, for the proposal of new ideas and even to use it in writing of several sections of a research project.

\section{References}

Allred, B. B., Findley, M. G., Nielson, D. \& Sharman, J. C. (2017) "Anonymous shell companies: A global audit study and field experiment in 176 countries", Journal of International Business Studies, vol. 48(5): 596-619

Alstadsæter, A., Johannesen, N. \& Zucman, G. (2018) "Who owns the wealth in tax havens? Macro evidence and implications for global inequality", Journal of Public Economics, vol. 162: 89-100

Bradbury, M. E. (2012) "Why you don't get published", Accounting and Finance, vol. 52(2): 343-358

Faff, R. W. (2015) "A simple template for pitching research", Accounting \& Finance, vol. 55(2): 311-336

Faff, R. W. (2017) "Pitching research", Available at SSRN: https://dx.doi.org/ $10.2139 / \mathrm{ssrn} .2462059$

Faff, R. W. (2018) "Pitching research", Available at SSRN: https://dx.doi.org/ 10.2139/ssrn.2462059

Grant, A. M. \& Pollock, T. G. (2011) "Publishing in AMJ ??? part 3: Setting the hook", The Academy of Management Journal, vol. 54(5): 873-879

Rekker, S. (2016) "Converting planetary boundaries into action, a new approach to meeting global greenhouse gas targets", Accounting and Management Information Systems, vol. 15(1): 160-167

Salehudin, I. (2017) "Reverse engineering' the pitching research template: A simple tool to help understand the academic literature", J Accounting and Management Information Systems, vol. 16(1): 203-210 
Song, X., Hu, Z., Du, J. \& Sheng, Z. (2014) "Application of machine learning methods to risk assessment of financial statement fraud: Evidence from china", Journal of Forecasting, vol. 33(8): 611-626

Stokes, D. (2013) "Generating innovative research ideas", Accounting and Management Information Systems, vol. 12(2): 144

Transparency International (2017) Cowdock, B. Hiding in plain sight: How UK companies are used to launder corrupt wealth, United Kingdom, http://www.transparency.org.uk/publications/hiding-in-plainsight/\#.WwInj3eFO70 [on-line access: March 15 ${ }^{\text {th }} 2018$ ]

Unda, L. A. (2015) "Board of Directors characteristics and credit union financial performance: A pitch", Accounting \& Finance, vol. 55(2): 353-360

Wallin, A. \& Spry, A. (2016) "The role of corporate versus product brand dominance in brand portfolio overlap: A pitch", Accounting and Management Information Systems, vol. 15(2): 434-439 